\title{
Simulation and sensitivity analysis for biodiesel production in a reactive distillation column
}

\author{
Madhu Agarwal', Kailash Singh ${ }^{2}$, S.P. Chaurasia ${ }^{3}$ \\ Malaviya National Institute of Technology, Department of Chemical Engineering, Jaipur-302017, India \\ Corresponding author's: e-mail: ${ }^{1}$ amadhunaresh@gmail.com, ${ }^{2}$ bksingh.mnit@gmail.com, ${ }^{3}$ cchch3@rediffmail.com
}

\begin{abstract}
The conventional process for biodiesel production by transesterification is still expensive due to a need of high excess of alcohol required and its recovery by distillation. The use of a reactive distillation process can reduce the amount of alcohol in the feed stream as it works on a simultaneous reaction and separation. In the present study, a mathematical model has been developed for biodiesel production from triglycerides in a reactive distillation column, which has been validated with the reported data and CHEMCAD results. The effects of process parameters such as methanol to oil feed ratio, feed temperature, and reaction time have been investigated. The sensitivity analysis shows that yield of ester increases with methanol to oil ratio and number of stages, however, it decreases with flow rate. The MATLAB simulated results show that methanol to oil molar ratio of 5:1 produces $90 \%$ (by wt.) of methyl ester in a residence time of 4.7 minutes.
\end{abstract}

Keywords: Biodiesel, reactive distillation, modeling, simulation, transesterification, sensitivity analysis.

\section{INTRODUCTION}

Need for renewable energy has gained much importance nowadays due to increased demand of energy to sustain the human development. Biodiesel is one of such renewable energy that can substitute diesel oil produced from petroleum and is produced from vegetable oils and animal fats. Generally, it is formed by transesterification reaction of triglycerides in the vegetable oil or animal fat with short chain aliphatic alcohols. It is biodegradable, nontoxic, and essentially free of sulfur and aromatics. Methanol and ethanol are the preferred alcohols to be used for the transesterification reaction ${ }^{1}$. The commercialization production of biodiesel from vegetable oils/fats still have drawbacks due to a high cost of the vegetable oil and the purification of biodiesel product. Both batch and continuous processes utilize almost $100 \%$ excess alcohol than the stoichiometric molar requirement (3:1) in order to drive the transesterification reaction to a completion and to produce the maximum amount of biodiesel per unit consumption of oil ${ }^{2}$. This excess alcohol has to be recovered by a separate distillation column. The use of separate distillation column for alcohol recovery increases capital as well as operating cost. Therefore, new alternatives are needed to be explored for the reaction and the product separation to minimize the cost of the process without affecting the yield and quality of biodiesel for which reactive distillation (RD) or catalytic distillation could be a prominent alternative technique.

Application of the reactive distillation process for biodiesel production can save the cost by eliminating the need of the reactor and the separation unit separately. It is a hybrid process that combines the reaction and separation in a single equipment. The product is removed at the same time when it is formed. This characteristic makes it possible to overcome the equilibrium thermodynamics of the reaction, reaching high conversion and selectivity ${ }^{3-5}$. Reactive distillation technique is more effective for reversible reactions such as esterification of fatty acids ${ }^{6-8}$ and transesterification to produce biodiesel'. Bhatia et al. ${ }^{10}$ proposed an optimi- zed reactive distillation process for the production of isopropyl palmitate by palmitic acid esterification with isopropanol based on the experimental and simulation results. The RD technique can reduce the use of excess alcohol in the feeding stream, which reduces the cost in downstream alcohol recovery processes; maintain a high alcohol-to-oil molar ratio inside the RD reactor, which ensures the completion of the transesterification of seed oil to biodiese ${ }^{11}$. Catalytic reactive distillation has several advantages such as shifting the chemical equilibrium by a continuous removal of the products, easy separation of the catalyst from the reaction mixture, utilization of heat of reaction for mass transfer in case of exothermic reaction, and absence of undesired side reactions ${ }^{12}$. The synthesis of fatty acid esters by heavy alcohols such as propanol, butanol, etc. using catalytic reactive distillation has been studied by many researchers. The synthesis of 2-ethylhexyl dodecanoate in the reactive distillation column (RDC) was reported by Omota et $\mathrm{al}^{8}$. Theoretically, the possibility of producing 2-ethyl hexanol and methanol ester with oleic acid and lauric acid has been investigated by Matallana et al. ${ }^{13}$ using Aspen Plus. Thotla and Mahajani ${ }^{14}$ used RDC with side draw for esterification of lactic acid, aldol condensation of acetone, and esterification of fatty acid by methanol. They reported better yield with side draw than without it. Singh et al. ${ }^{11}$ developed and used a laboratory scale sieve-tray RDC to study the transesterification of seed oil. They showed that methanol to oil molar ratio of $4: 1$ and a column temperature of $65^{\circ} \mathrm{C}$ produces biodiesel that met the ASTM standards. Steinigeweg and Gmehling ${ }^{15}$ used reactive distillation process for the production of decanoic acid methyl esters by esterification of the fatty acid decanoic acid with methanol. They varied operating conditions to determine the influence of reactant ratio, reflux ratio, pressure, and distillate to feed ratio, size of the reactive section, and role of a prereactor on yield of ester. $\mathrm{He}^{\mathbf{1 6}}$ designed and tested a bench-scale $\mathrm{RD}$ reactor for biodiesel preparation. He showed that the bench-scale RD process can produce biodiesel at a production rate of about $75 \mathrm{ml} / \mathrm{min}$ continuously with 
an alcohol to oil ratio of 4:1. Kiss et $a l^{2}$ demonstrated through simulations that combining metal oxide catalysts with reactive distillation technology is a feasible and advantageous solution for biodiesel production. Santander et al. ${ }^{17}$ used the response surface methodology and Aspen Plus software for simulating the castor oil biodiesel production by reactive distillation and found ethanol to oil molar ratio $31.6 \%$ lower than that in the conventional process.

In the present study, a steady state model has been developed for the production of biodiesel in a RD column from triglyceride (triolein) and methanol in the presence of $\mathrm{NaOH}$. A MATLAB program was written to solve the resulting equations. This model was validated by comparing the simulated results with the reported data from literature ${ }^{\mathbf{1 6}}$. This model was also used to investigate the effect of the reactant ratio, the number of equilibrium stages, the feed tray location, and the feed flow rate on the yield of biodiesel.

\section{MATHEMATICAL MODEL}

To develop a mathematical model of reactive distillation for biodiesel production, mass and energy balance as well as the thermodynamic equilibrium equations on each tray are written. The stages are counted from top to bottom as shown in the block diagram of the RDC in Fig. 1. The model is valid under the following assumptions:

I. All the plates are equilibrium stages.

II. Vapor phase is an ideal gas mixture.

III. Reaction takes place only in the liquid phase.

IV. Constant operating pressure and total condenser with no sub-cooling.

V. Heat generated due to a chemical reaction is taken into consideration.

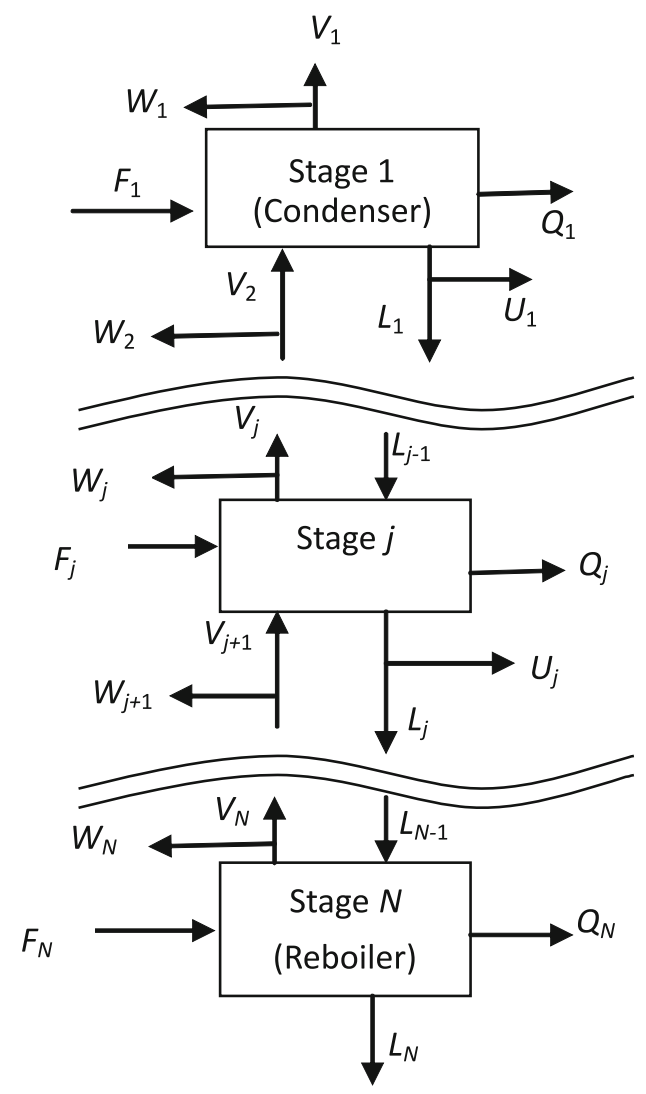

Figure 1. Block Diagram of Reactive Distillation Column
VI. Vapor phase hold up is assumed to be negligible as compared to the liquid phase hold up on each stage.

\section{Mass balance}

Mass balance on each stage of column is given by $M_{i, j} \equiv l_{i, j}\left(1+s_{j}\right)+v_{i, j}\left(1+S_{j}\right)-l_{i, j-1}-v_{i, j+1}-F_{j} z_{i, j}-G_{j} \sum_{k=1}^{n_{r}} R_{i, k, j}=0$

where, $v_{i, j}=y_{i, j} V_{j}$ and $l_{i, j}=x_{i, j} L_{j}, s_{j}=\frac{U_{j}}{L_{j}}, S_{j}=\frac{W_{j}}{V_{j}}$, $j=1 \ldots N$ and $i=1 \ldots n_{c}$

For the top stage $(j=1), W_{1}=0$. For the total condenser, $V_{1}=0$. The distillate rate was assumed to be zero for the total reflux condition. As there is no side stream withdrawal from stage 2 onwards, $s_{2}=s_{3}=\ldots=s_{N}=0$.

\section{Equilibrium relationships}

The most commonly used vapour-liquid equilibrium relationship is the modified Raoult's law, which is valid for low to moderate pressure:

$E_{i, j} \equiv K_{i, j} l_{i, j}\left(\frac{V_{j}}{L_{j}}\right)-v_{i, j}=0$

For partial condenser, $j=1 \ldots N$ and $i=1 \ldots n_{c}$. For total condenser, $j=2 \ldots N$ and $i=1 \ldots n_{c}$ and $E_{i, 1} \equiv v_{i, 1}=0$.

\section{Enthalpy balance}

$H_{j} \equiv H_{L j}\left(1+s_{j}\right) L_{j}+H_{V j}\left(1+S_{j}\right) V_{j}-H_{L j-1} L_{j-1}-H_{V j+1} V_{j+1}$

$-H_{F j} F_{j}+Q_{j}-G_{j} \sum_{k=1}^{n_{r}} R_{i r e f, k, j} \Delta H_{R, \text { ref }, k}=0$

where $j=1 \ldots N$. If bottoms rate is specified in place of reboiler heat duty then

$H_{N} \equiv L_{N}-B=0$

Summation equations

$\sum_{i=1}^{n_{c}} l_{i, j}=L_{j}, j=1, \ldots, N$
$\sum_{i=1}^{n_{c}} v_{i, j}=V_{j}, j=1, \ldots, N$

\section{Reaction kinetics}

Triglyceride (oils/fats) reacts with alcohol in the presence of the catalyst to give fatty acid alkyl esters and glycerol. The reaction proceeds in three steps as shown below:

$$
\begin{gathered}
\text { Triglyceride + ROH } \underset{\mathrm{k}_{2}}{\stackrel{k_{1}}{\Leftrightarrow}} \text { Diglyceride + RCOOR } \\
\text { Diglyceride + ROH } \underset{\mathrm{k}_{4}}{\stackrel{k_{3}}{\Leftrightarrow}} \text { Monoglyceride + RCOOR } \\
\text { Monoglyceride }+\mathrm{ROH} \underset{\mathrm{k}_{6}}{\stackrel{k_{5}}{\Leftrightarrow}} \text { Glycerol + } \mathrm{RCOOR}_{3}
\end{gathered}
$$

where $\mathrm{R}_{1}, \mathrm{R}_{2}$, and $\mathrm{R}_{3}$ are the fatty acid chains associated with glycerol in triglyceride. $K_{1}, K_{2}, K_{3}$ are equilibrium constants, $K_{1}=k_{1} / k_{2}, K_{2}=k_{3} / k_{4}$, and $K_{3}=k_{5} / k_{6}$ where $k_{1}$, $k_{2}, \ldots, k_{6}$ are forward and backward rate constants. The reaction rates of each reaction are as follows: 
$r_{1}=k_{1} C_{\mathrm{TG}} C_{\mathrm{ROH}}-k_{2} C_{\mathrm{DG}} C_{\mathrm{AE}}$

$r_{2}=k_{3} C_{\mathrm{DG}} C_{\mathrm{ROH}}-k_{4} C_{\mathrm{MG}} C_{\mathrm{AE}}$

$r_{3}=k_{5} C_{\mathrm{MG}} C_{\mathrm{ROH}}-k_{6} C_{\mathrm{G}} C_{\mathrm{AE}}$

where $C_{\mathrm{TG}}, C_{\mathrm{DG}}, C_{\mathrm{MG}}, C_{\mathrm{G}}, C_{\mathrm{AE}}$ and $C_{\mathrm{ROH}}$ represent the concentration of triglyceride, diglyceride, monoglyceride, glycerol, alkyl ester, and alcohol respectively. Forward and backward the rate constants are given by

$k=k^{0} \exp \left(\frac{-E}{R T}\right)$

The kinetic parameters are as shown in Table 1 . The heat of the reaction is $\Delta H_{R}=-5.07 \times 10^{3} \mathrm{~J} / \mathrm{mol}$ for each reaction, calculated from the heat of the formation data.

Table 1. Frequency factor and activation energy [17]

\begin{tabular}{|l|c|}
\hline Constants & Value of constant \\
\hline$k_{1}{ }^{0}\left(\mathrm{~mol}^{-1}\right.$ litre $\left.\mathrm{min}^{-1}\right)$ & $1.469 \times 10^{8}$ \\
\hline$E_{1}(\mathrm{cal} / \mathrm{mol})$ & 14040 \\
\hline$k_{2}{ }^{0}\left(\mathrm{~mol}^{-1}\right.$ litre $\left.\mathrm{min}^{-1}\right)$ & 105100 \\
\hline$E_{2}(\mathrm{cal} / \mathrm{mol})$ & 10739 \\
\hline$k_{3}{ }^{0}\left(\mathrm{~mol}^{-1}\right.$ litre $\left.\mathrm{min}^{-1}\right)$ & $1.19 \times 10^{10}$ \\
\hline$E_{3}\left(\mathrm{call}^{1} / \mathrm{mol}\right)$ & $1.725 \times 10^{8}$ \\
\hline$k_{4}{ }^{0}\left(\mathrm{~mol}^{-1}\right.$ litre $\left.\mathrm{min}^{-1}\right)$ & 13907 \\
\hline$E_{4}\left(\mathrm{cal} / \mathrm{mol}^{-1}\right)$ & 24940 \\
\hline$k_{5}{ }^{0}\left(\mathrm{~mol} l^{-1}\right.$ litre $\left.\mathrm{min}^{-1}\right)$ & 7173 \\
\hline$E_{5}\left(\mathrm{cal} / \mathrm{mol}^{0}\right)$ & 627700 \\
\hline$k_{6}{ }^{0}\left(\mathrm{~mol}{ }^{-1}\right.$ litre $\left.\mathrm{min}^{-1}\right)$ & 10997 \\
\hline$E_{6}(\mathrm{cal} / \mathrm{mol})$ & \\
\hline
\end{tabular}

\section{Degree of Freedom Analysis}

The number of equations in Mass balance $=N n_{c}$

The number of equations in Equilibrium relationship $=N n_{c}$

The number of equations in Heat balance $=N$

The total number of equations $=N\left(2 n_{c}+1\right)$

The number of variables

$v_{i, j}, i=1 \ldots n_{c}, j=1 \ldots N: N+n_{c}$ variables

$T_{j}, j=1 \ldots N \quad: N$ variables

$l_{i, j}, i=1 \ldots n_{c}, j=1: N \quad: N+n_{c}$ variables

The total number of variables $=N\left(2 n_{c}+1\right)$

Therefore the Number of equations $=$ the Number of variables.

In the present study, the variables which have been specified are pressure, distillate rate, reflux ratio, $F_{j}$, and $z_{i, j}$.

\section{Simulation Methodology}

The column was simulated assuming 11 stages including the reboiler. The feed was introduced at the upper stage and the reaction took place on all the stages. Each reactive stage has $300 \mathrm{ml}$ holdup The kinetic model proposed by Bambase et al. ${ }^{18}$ was employed. The simulation was carried out by solving the system algebraic equations simultaneously using Newton's method ${ }^{19}$ in MATLAB ${ }^{\circledR}$. Composition, temperature, and alkyl ester purity were obtained on all stages assuming infinite reflux ratio. The temperature and vapor phase composition were calculated by the bubble-point calculation using the "Extended Antoine" equation:

$P^{\text {sat }}=\exp \left\{A+\frac{B}{T}+C \ln T+D T^{E}\right\}$ where, $A, B, C, D$, and $E$ are the Antoine constants; $T$ and $P$ are absolute temperature and vapor pressure, respectively. The algorithm flow chart for solving the steady state equations is shown in Fig. 2.

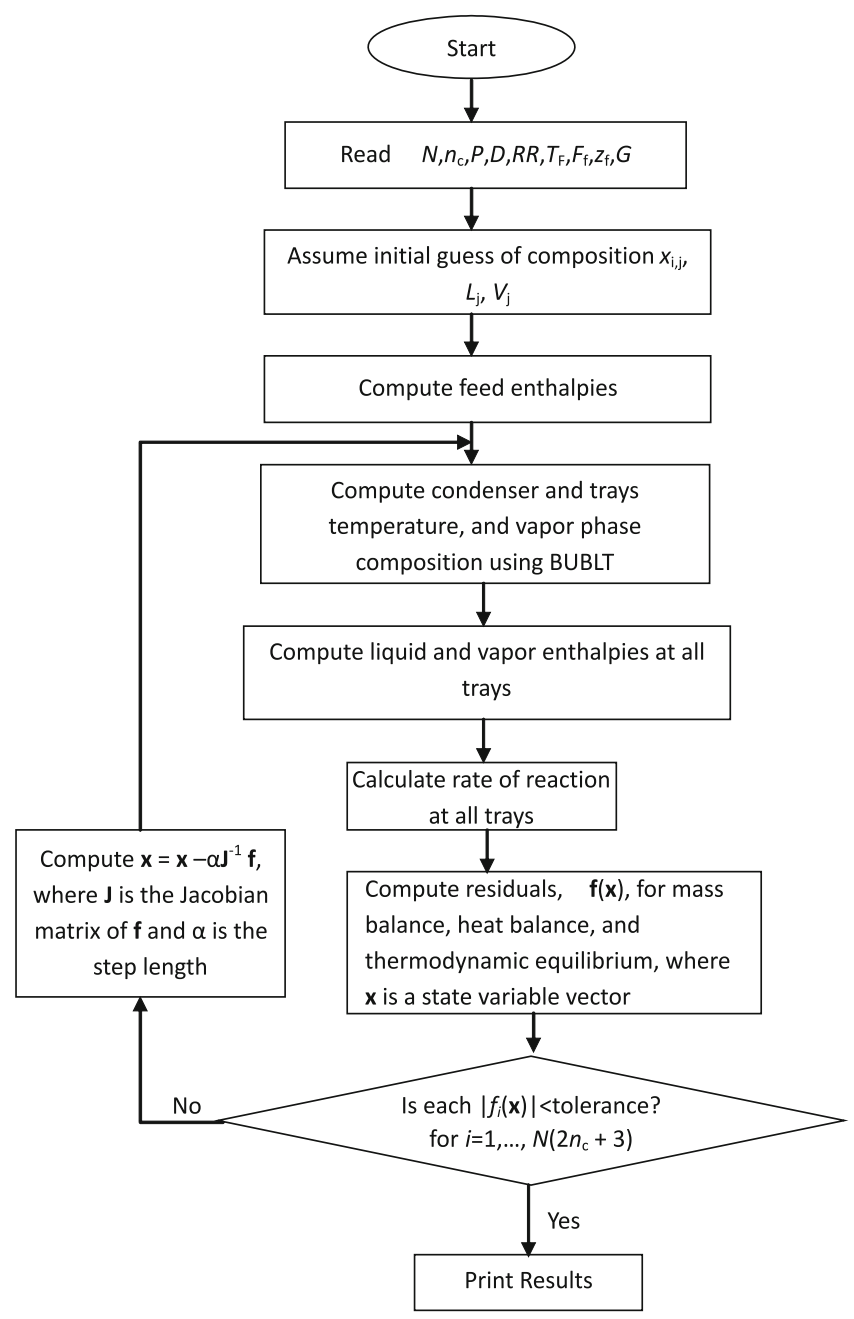

Figure 2. Algorithm flow chart for solving model equations

\section{RESULTS AND DISCUSSION}

The model equations were solved in MATLAB and the results were also compared with those obtained in CHEMCAD software.

\section{Tower profile}

A reactive distillation column with 10 numbers of trays, the total condenser, and the reboiler was considered for simulation. The feed containing oil, methanol, and the catalyst was fed on the top tray. The reactive zone thus lied from the top tray to the reboiler. The column specifications are shown in Table 2. The steady state column composition and temperature profile were obtained by running the MATLAB simulation as shown in Fig. 3(a) and (b). For the calculation of weight fraction in the column, glycerol and methanol have been excluded as these will be separated out in a successive unit.

From Fig. 3a it is clear that the concentration (wt. fraction) of methyl ester, i.e. product concentration increases from the top to the bottom tray and is maximum in the reboiler. The intermediates DG and MG remain in the low amount throughout the column due to fast consumption in the chemical reactions. The TG reactant shows a continuous decreasing trend confirming 


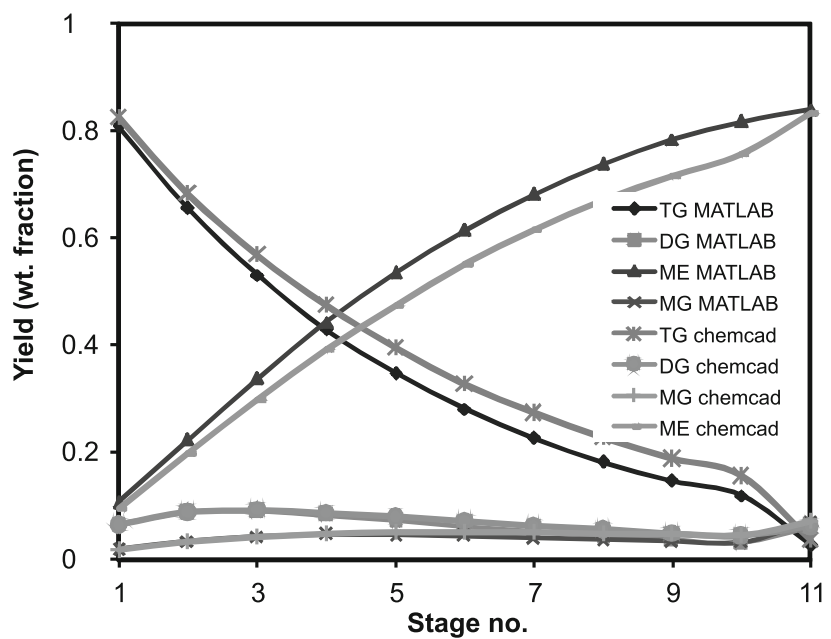

(a)

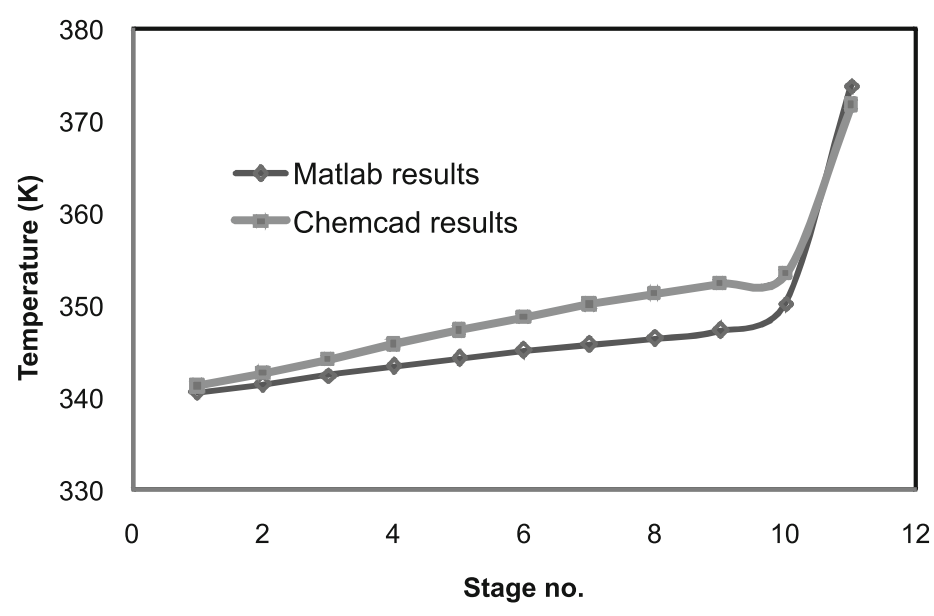

(b)

Figure 3. (a) Composition (b) Temperature profile in the column

Table 2. Column specification for biodiesel production

\begin{tabular}{|l|c|}
\hline $\begin{array}{l}\text { Number of ideal separation stages } \\
\text { (including reboiler) }\end{array}$ & 11 \\
\hline Feed flow rate at tray 1 & $0.00598 \mathrm{mols} / \mathrm{s}$ \\
\hline $\begin{array}{l}\text { Feed composition at tray } 1 \\
\text { (triglyceride and methanol in mole } \\
\text { fraction) }\end{array}$ & $x_{\mathrm{TG}}=0.2, x_{\text {Methanol }}=0.8$ \\
\hline Feed temperature & $328 \mathrm{~K}$ \\
\hline Distillate rate & $5.98 \times 10^{-5} \mathrm{moles} / \mathrm{s}$ \\
\hline Reboiler volume & 0.21 liter \\
\hline Reaction volume on each tray & 0.011 liter \\
\hline Column pressure & $1.013 \mathrm{bar}$ \\
\hline Reflux ratio $L_{0} / D$ & 114.3 \\
\hline
\end{tabular}

its consumption in reaction. The maximum yield of 84 wt $\%$ of methyl ester was obtained in the reboiler. A conversion of $97 \%$ was achieved in the column.

The temperature profile of the column is shown in Fig. 3b. It can be seen from the figure that the temperature increases steadily from top to bottom and shoots up in the reboiler due to the accumulation of the high boiling components such as methyl ester, tri-, di-, mono-glycerides, and glycerol in the bottoms.

\section{Model validation}

The column profile was obtained with respect to residence time in the column in order to validate the model with the experimental data available in the literature. The experimental data of $\mathrm{He}^{16}$ and Singh et al. ${ }^{11}$ were considered for model validation as shown in Fig. 4a-d. A good match of the simulation and experimental data is evident from these figures. It can be seen that most of the reaction takes place in the column with a reaction time of less than $2 \mathrm{~min}$. The reboiler having 3 minutes of residence time shows little reaction due to the vaporization of methanol from the liquid phase. The concentration profile obtained for RDC for TG, $\mathrm{DG}, \mathrm{MG}$, and $\mathrm{ME}$ is similar to the batch reactor as reported by Noureddini and $\mathrm{Zhu}^{20}$, Freedman et al. $^{21}$, and Darnoko and Cheryan ${ }^{22}$.

\section{Sensitivity analysis of the column}

The effects of various parameters on the yield of biodiesel were investigated as shown in Fig. 5a-d. The effect of molar ratio of methanol to oil on the yield of biodiesel is shown in Fig. 5a. It can be seen from the figure that the yield of biodiesel increases with increase in methanol amount. Similar results have been shown by Singh et al. ${ }^{11}$. The yield increases from $72.42 \mathrm{wt} \%$ to 84 wt $\%$ on increasing the molar ratio of methanol to oil from 3 to 4 , however, it increases only up to $90.3 \mathrm{wt}$ $\%$ when the ratio is increased from 4 to 5 . Beyond the ratio of $5: 1$, there is only a slight change in the yield. Therefore, the ratio of 5:1 is sufficient in a reactive distillation beyond this ratio. Simasatitkul et al. ${ }^{23}$ also reported the molar ratio of 4.5:1 to be optimum for the production of biodiesel in three reactive staged reactive distillation column. Moreover, a high amount of alcohol will need a large column to handle the unreacted methanol. The TG reactant and the intermediates DG and MG continuously decrease with an increase in the methanol amount due to enhancement in conversion.

The effect of the feed flow rate on the yield of biodiesel obtained is as shown in Fig. 5b. It can be seen from this figure that the yield of biodiesel decreases with the increase in the feed flow rate due to a decrease in the residence time. The decrease in the yield is more pronounced after $0.012 \mathrm{~mol} / \mathrm{s}$ of feed flow rate. The intermediates formed remain in a low amount.

The effect of the feed tray location on the yield of biodiesel from RDC is shown in Fig. 5c. It can be observed from this figure that the yield of biodiesel slightly decreases with the change in the feed tray location from the top towards the bottom. The amount of the intermediates formed remains almost constant. The maximum yield is obtained with the top tray being the feed tray as the number of reactive stages is maximum in this case.

To find the effect of the total number of trays in RDC on the yield of biodiesel, simulation results were obtained by changing the total number of trays in the column as shown in Fig. 5d. It can be seen from these figures that with increasing the number of trays in the column from 8 to 18, the yield of biodiesel increases from 83 to $85.5 \%$ only. This may be due to the fact that most of the reaction is carried out in the upper trays because of a large fraction of methanol lying on these trays. 


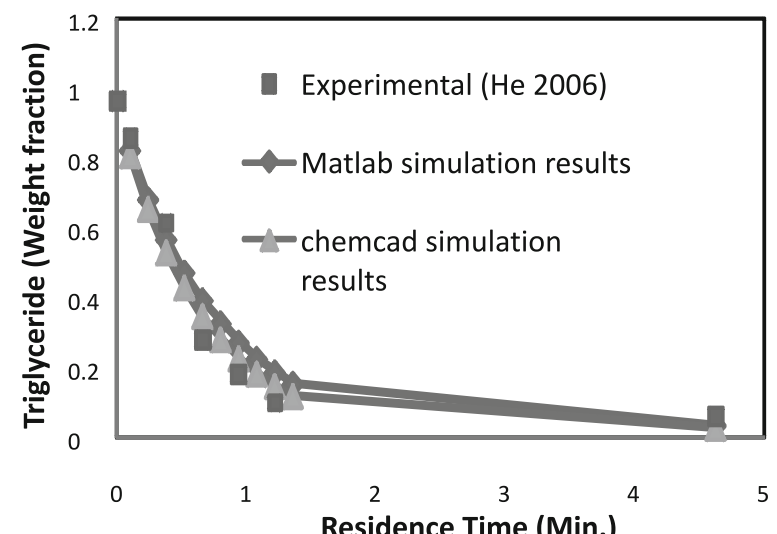

a)

Residence Time (Min.)

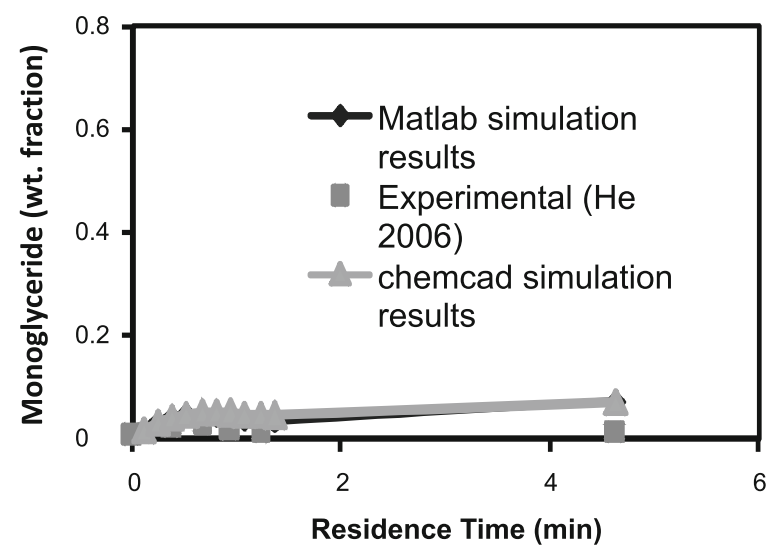

c)
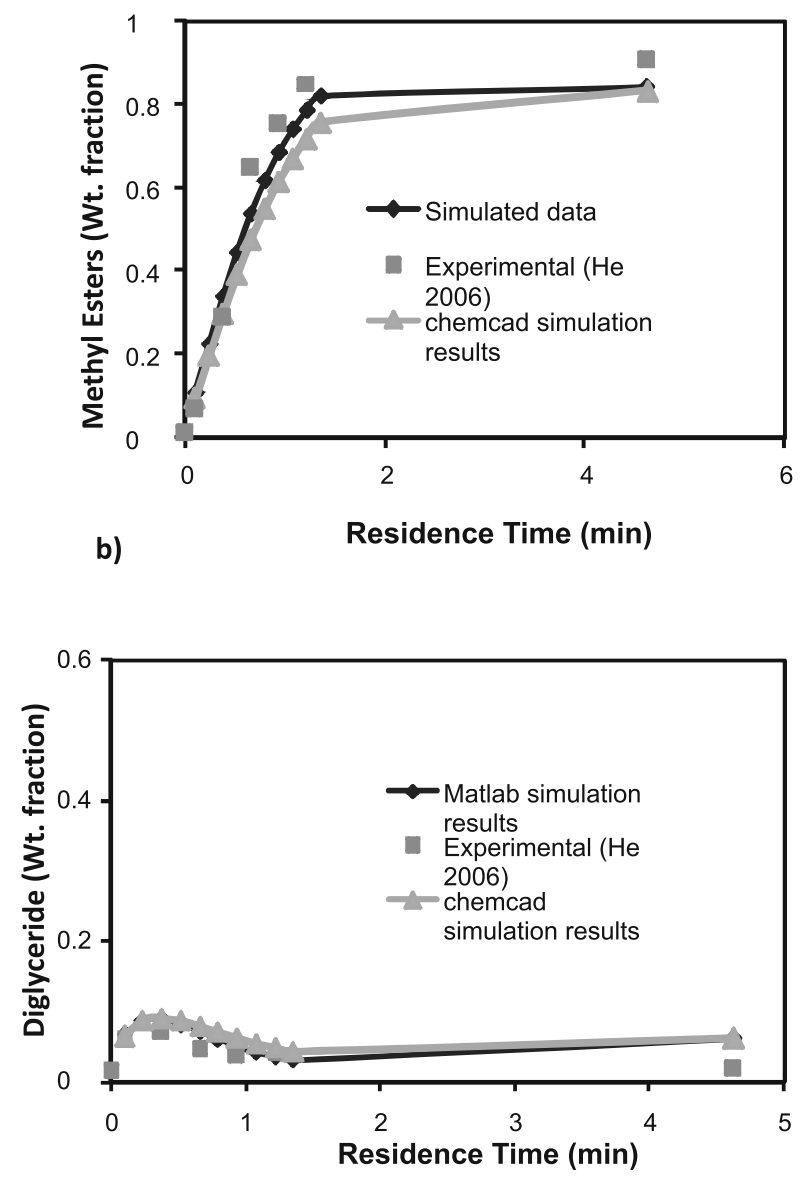

d)

Figure 4. Experimental and simulated profile in the reactive distillation column (a) triglyceride (b) methyl ester (c) mono-glyceride (d) di-glyceride

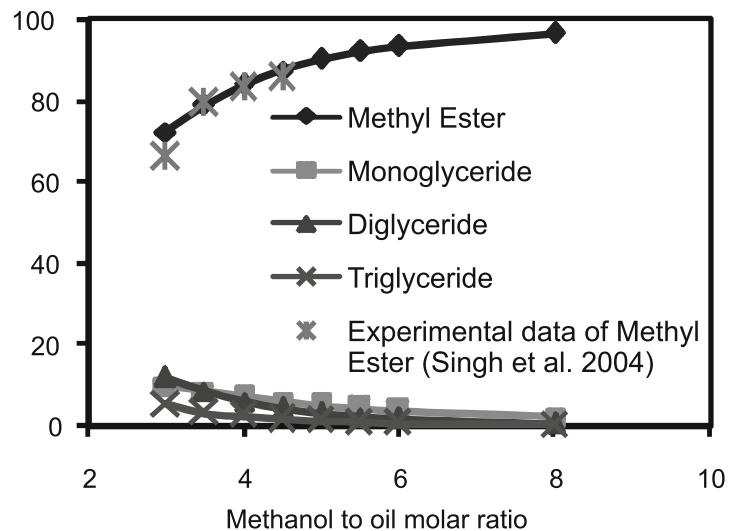

(a)

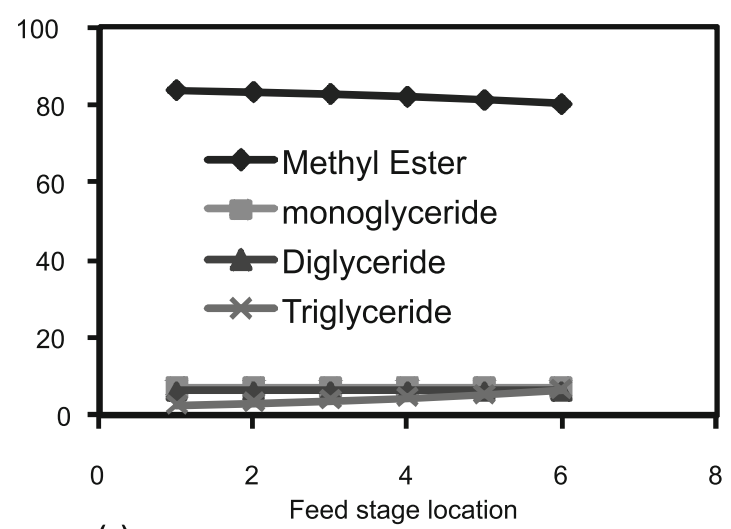

(c)

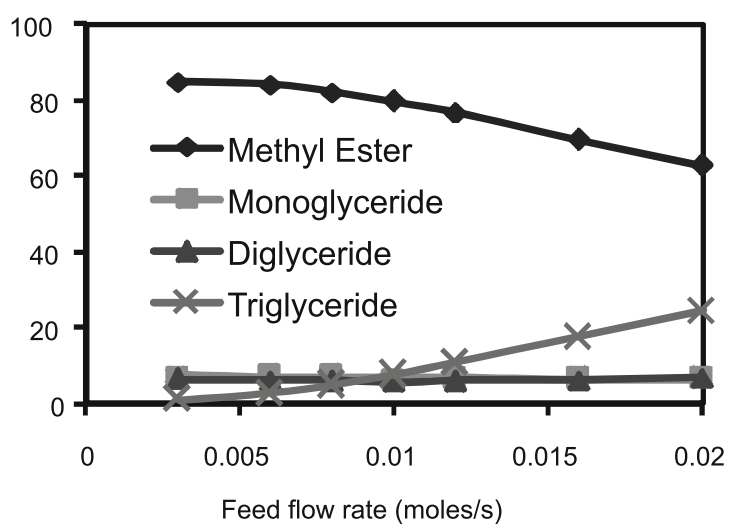

(b)

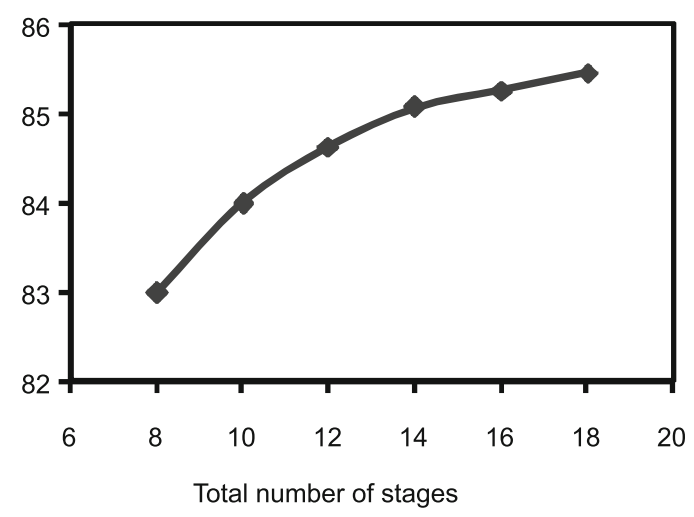

(d)

Figure 5. Effect of (a) methanol to oil molar ratio (b) feed flow rate (c) feed stage location (d) total number of stages on yield 


\section{CONCLUSIONS}

A model developed to predict the composition and the yield of biodiesel production from pure TG (triolein) in a RDC using methanol and $\mathrm{NaOH}$ catalyst was simulated using MATLAB to obtain the column profile. The tower profile obtained in MATLAB was also compared with the CHEMCAD result. It was observed that both results are similar. This model was validated with the reported data. The RDC can be effectively used for the transesterification of vegetable oils as $97 \%$ conversion of triglyceride was predicted in a residence time of 4.7 minutes. Most of the reaction takes place in the column and small conversion in reboiler. Sensitivity analysis of the column revealed that the yield of ester increases with methanol to oil ratio, the number of trays and decreases with the flow rate. Methanol to oil ratio of $5: 1$ gives $90.3 \%$ yield, however beyond this ratio, yield is not much improved. High methanol to oil ratio $(>5: 1)$ can lead to methanol flooding in the column as it is the most volatile component in the system.

\section{Nomenclature}

$C_{i} \quad$ concentration of $i^{\text {th }}$ component (mol/litre)

$D$ distillate flow rate $(\mathrm{mol} / \mathrm{s})$

$G_{j} \quad$ Volume of $j^{\text {th }}$ stage (liter)

$\Delta H_{R} \quad$ heat of reaction $(\mathrm{J} / \mathrm{mol})$

$H_{L j} \quad$ liquid enthalpy on $j^{\text {th }}$ stage

$H_{V j} \quad$ vapour enthalpy on jth stage

$H_{F j} \quad$ Feed enthalpy on $j^{\text {th }}$ stage

$i_{\text {ref } k} \quad$ reference component number in $k^{\text {th }}$ reaction

$K_{i, j} \quad$ Equilibrium constant $=\gamma_{i, j} P_{i, j}^{\text {sat }} / P$

$l_{i, j} \quad$ liquid flow rate of $i^{\text {th }}$ component from $j^{\text {th }}$ stage

$L_{j} \quad$ Total liquid flow rate from $j^{\text {th }}$ plate $(\mathrm{mol} / \mathrm{s})=\sum l_{i, j}, i=1: n_{c}$

$n_{c} \quad$ no. of components $=6$

$n_{r} \quad$ no. of reactions involved

$N \quad$ no. of stages including reboiler

$P \quad$ pressure $\left(\mathrm{N} / \mathrm{m}^{2}\right)$

$P_{i, j}^{\text {sat }} \quad$ vapor pressure of $i^{\text {th }}$ component on $j^{\text {th }}$ stage

$Q_{j} \quad$ Heat removed from stage $j$

$R_{i, k, j} \quad$ rate of reaction of $i^{\text {th }}$ component on $j^{\text {th }}$ plate for $k^{\text {th }}$ reaction

$\begin{array}{ll}s_{j} & U_{\mathrm{j}} / L_{\mathrm{j}} \\ S_{j} & W_{\mathrm{j}} / V\end{array}$

$T \quad$ temperature $(\mathrm{K})$

$U_{j} \quad$ Flow rate of liquid side stream withdrawn from jth stage

$v_{i, j} \quad$ Vapor flow rate of $i^{\text {th }}$ component from $j^{\text {th }}$ stage

$V_{j} \quad$ Total vapor flow rate leaving $j^{\text {th }}$ tray $(\mathrm{mol} / \mathrm{s})$

$F_{j} \quad$ Feed flow rate on $j^{\text {th }}$ tray $(\mathrm{mol} / \mathrm{s})$

$W_{j} \quad$ vapour flow rate withdrawn from $j^{\text {th }}$ tray $(\mathrm{mol} / \mathrm{s})$

$z_{i, j} \quad$ mole fraction of $i^{\text {th }}$ component in liquid phase on $j^{\text {th }}$ plate

$\gamma_{i, j} \quad$ activity coefficient of $i^{\text {th }}$ component on $j^{\text {th }}$ tray

\section{Subscripts}

$f \quad$ forward

$i \quad$ component number $\left(1\right.$ to $\left.n_{c}\right)$

$j \quad$ stage number $(0$ to $N+1)$

$r$ reverse

$\begin{array}{ll}\text { Abbreviations } \\ \text { TG } & \text { Triglyceride } \\ \text { DG } & \text { Diglyceride } \\ \text { MG } & \text { Monoglyceride } \\ \text { ME } & \text { Methyl ester } \\ \text { G } & \text { Glycerol }\end{array}$

\section{LITERATURE CITED}

1. Fangrui, M. \& Milford, A.H. (1999). Biodiesel production: a review. Bioresource Technology. 70 (1), 1-15. doi:10.1016/ S0960-8524(99)00025-5.

2. Kiss, A.A., Dimian, A.C. \& Rothenberg, G. (2008). Biodiesel by catalytic reactive distillation powered by metal oxides. Energy Fuels. 22 (1), 598-604.

3. Giessler, S., Danilov, R.Y., Pisarenko, R.Y., Serafimov, L.A., Hasebe, S. \& Hashimoto, I. (2001). Systematic structure generation for reactive distillation processes. Computers \& Chemical Engineering. 25 (1), 49-60. doi:10.1016/S00981354(00)00632-3.

4. He, B.B., Singh, A.P. \& Thompson, J.C. (2006). A novel continuous-flow reactor using reactive distillation for biodiesel production. Transactions of the ASABE. 49 (1), 107-112.

5. Pai, R.A., Doherty, M.F. \& Malone, M.F. (2002). Design of reactive extraction systems for bioproduct recovery. AIChE Journal. 48 (3), 514-526. DOI: 10.1002/aic.690480310.

6. Chin, S.Y., Mohamed, A.R., Ahmad, A.L. \& Bhatia, S. (2006). Esterification of palmitic acid with iso-propanol in a catalytic distillation column: Modeling and simulation studies. International Journal of Chemical Reactor Engineering. 4 (4), 32.

7. Kiss, A.A., Omota, F., Dimian, A.C. \& Rothenberg, G. (2006). The heterogeneous advantage: biodiesel by catalytic reactive distillation. Topics in Catalysis. 40 (1), 141-150. DOI: 10.1007/s11244-006-0116-4.

8. Omota, F., Dimian, A.C. \& Bliek, A. (2003). Fatty acid esterification by reactive distillation. Chemical Engineering Science. 58, 3159-3174. doi:10.1016/S0009-2509(03)00165-9.

9. He, B.B., Singh, A.P. \& Thompson, J.C. (2005). Experimental optimization of a continuous-flow reactive distillation reactor for biodiesel production. Transactions of the ASAE. 48 (6), 2237-2243.

10. Bhatia, S., Ahmad, A.L., Mohamed, A.R. \& Chin, S.Y. (2006). Production of isopropyl palmitate in a catalytic distillation column: Experimental studies. Chemical Engineering Science. 61 (22), 7436-7447. doi:10.1016/j.ces.2006.08.039.

11. Singh, A.P., Thompson, J.C. \& He, B.B. In A continuous-flow reactive distillation reactor for biodiesel preparation from seed oils, ASAE/CSAE Annual International Meeting, Ottawa, Ontario, Canada, 1-4 August, 2004; Ottawa, Ontario, Canada, 2004. Paper number 046071.

12. Taylor, R. \& Krishna, R. (2000). Modelling reactive distillation. Chemical Engineering Science. 55 (22), 5183-5229. doi:10.1016/S0009-2509(00)00120-2.

13. Mattalana, L.G., Gutierrez, L.F. \& Cardona C.A. In Biodiesel Production by reactive distillation, $\mathrm{R}$ Distillation enpromer2005.eq.ufrj.br., 2005; 2005; pp 1-9.

14. Thotla, S. \& Mahajani, S. (2009). Reactive distillation with side draw. Chemical Engineering and Processing: Process Intensification. 48 (4), 927-937. DOI: 10.1016/j.cep.2008.12.007.

15. Steinigeweg, S. \& Gmehling, J. (2003). Esterification of a fatty acid by reactive distillation. Ind. Eng. Chem. Res. 42 (15), 3612-3619.

16. He, B. (2006.). A novel continuous-flow reactor using reactive distillation for biodiesel production. A report, National Institute of Advanced Transport Technology, University of Idaho.

17. Santandera, C.M.G., Sandra Marcela Gómez Rueda, Nívea De, Lima da Silvaa, Aline Carvalho da Costa, Rubens 
Maciel Filhoa, Regina, M. \& Maciela., W. (2010). Simulation of the reactive distillation process for biodiesel production. 20th European Symposium on Computer Aided Process Engineering - ESCAPE20.

18. Bambase, M.E., Nakamura, N., Tanaka, J. \& Matsumura, M. (2007). Kinetics of hydroxide-catalyzed methanolysis of crude sunflower oil for the production of fuel-grade methyl esters. Journal of Chemical Technology \& Biotechnology. 82 (3), 273-280. DOI: 10.1002/jctb.1666.

19. Gupta, S.K., Numerical methods for engineers. New Age International: New Delhi, 2006; p 422.

20. Noureddini, H. \& Zhu, D. (1997). Kinetics of transesterification of soybean oil. Journal of the American Oil Chemists Society. 74 (11), 1457-1463. DOI: 10.1007/s11746-997-0254-2.

21. Freedman, B., Butterfield, R.O. \& Pyrde, E. (1986). Transesterificationkinetics of soybean oil. J. Am. Oil Chem. Soc. 63, 1375-1380. DOI: 10.1007/BF02679606.

22. Darnoko, D. \& Cheryan, M. (2000). Kinetics of palm oil transesterification in a batch reactor. Journal of the American Oil Chemists' Society. 77 (12), 1263-1267. DOI: 10.1007/ s11746-000-0198-y.

23. Simasatitkul, L., Siricharnsakunchai, P., Patcharavorachot, Y., Assabumrungrat, S. \& Arpornwichanop, A. (2011). Reactive distillation for biodiesel production from soybean oil. Korean Journal of Chemical Engineering. 28 (3), 649-655. DOI: 10.1007/s11814-010-0440-z. 